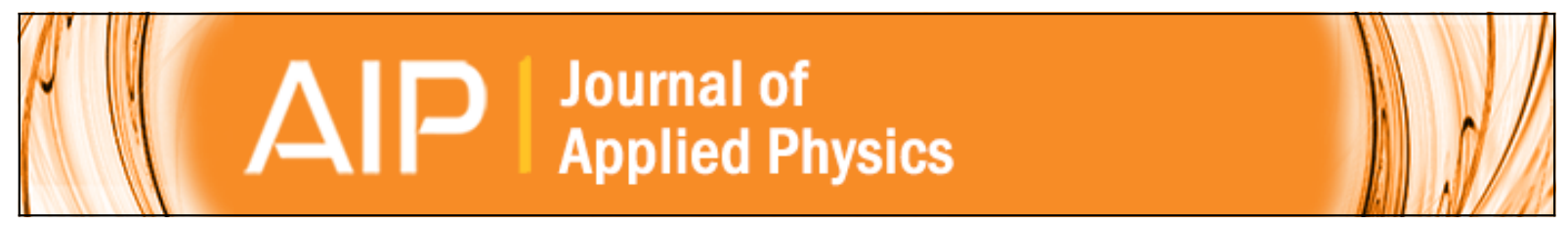

Photoluminescence behavior of Si nanocrystals as a function of the implantation temperature and excitation power density

U. S. Sias, L. Amaral, M. Behar, H. Boudinov, E. C. Moreira, and E. Ribeiro

Citation: Journal of Applied Physics 98, 034312 (2005); doi: 10.1063/1.1989437

View online: http://dx.doi.org/10.1063/1.1989437

View Table of Contents: http://scitation.aip.org/content/aip/journal/jap/98/3?ver=pdfcov

Published by the AIP Publishing

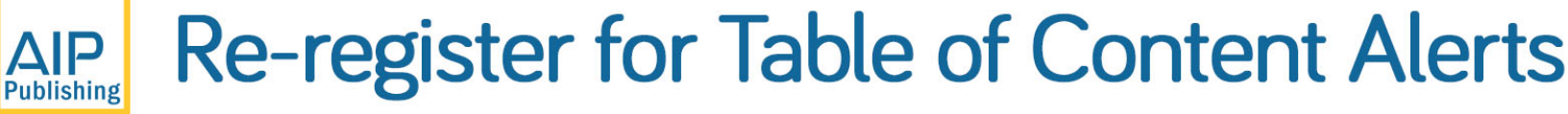

\section{Create a profile. \\ Sign up today!}




\title{
Photoluminescence behavior of Si nanocrystals as a function of the implantation temperature and excitation power density
}

\author{
U. S. Sias ${ }^{\mathrm{a})}$ \\ Instituto de Física-Universidade Federal do Rio Grande do Sul (UFRGS), C.P. 15051, 91501-970 Porto \\ Alegre, Rio Grande do Sul (RS), Brazil and Centro Federal de Educação Tecnológica-Rio Grande \\ do Sul (CEFET-RS), 96015-360 Pelotas, Rio Grande do Sul (RS), Brazil \\ L. Amaral, M. Behar, ${ }^{\text {b) }}$ and H. Boudinov \\ Instituto de Física-Universidade Federal do Rio Grande do Sul (UFRGS), C.P. 15051, 91501-970 Porto \\ Alegre, Rio Grande do Sul (RS), Brazil \\ E. C. Moreira \\ Universidade Estadual do Rio Grande do Sul, 92500-00 Unidade de Guaíba, \\ Rio Grande do Sul (RS), Brazil \\ E. Ribeiro \\ Departamento de Física-Universidade Federal do Parana (UFPR), C.P. 19044, 81531-990 Curitiba, \\ Parana (PR), Brazil
}

(Received 8 March 2005; accepted 6 June 2005; published online 10 August 2005)

\begin{abstract}
In this work we present a study of photoluminescence (PL) on Si nanocrystals (NC) produced by ion implantation on $\mathrm{SiO}_{2}$ targets at temperatures ranging between room temperature and $800{ }^{\circ} \mathrm{C}$ and subsequently annealed in $\mathrm{N}_{2}$ atmosphere. The PL measurements were performed at low excitation power density $\left(20 \mathrm{~mW} / \mathrm{cm}^{2}\right)$ in order to avoid nonlinear effects. Broad PL spectra were obtained, presenting a line-shape structure that can be reproduced by two superimposed peaks at around 780 and $950 \mathrm{~nm}$. We have observed that both PL intensity and line-shape change by varying the annealing as well as the implantation temperatures. Implantations performed at $400{ }^{\circ} \mathrm{C}$ or higher produce a remarkable effect in the PL line shape, evidenced by a strong redshift, and a striking intensity increase of the peak located at the long-wavelength side of the PL spectrum. In addition we have studied the PL dependence on the excitation power density (from 0.002 to $15 \mathrm{~W} / \mathrm{cm}^{2}$ ). The samples with broad NC size distribution containing large grains, as revealed by transmission electron microscopy observations presented a PL spectrum whose line shape was strongly dependent on the excitation power density. While high excitation power densities (saturation regime) induce only the short-wavelength part of the PL spectrum, low excitation power densities bring out the appearance of the hidden long-wavelength part of the emission. The present results are explained by current models. (C) 2005 American Institute of Physics. [DOI: 10.1063/1.1989437]
\end{abstract}

\section{INTRODUCTION}

Since the discovery of intense visible-light emission in porous $\mathrm{Si}$ and in $\mathrm{Si}$ nanocrystallites an ongoing research activity has been devoted in studying Si nanostructures due to their promising applications in optoelectronic and photonic devices. ${ }^{1-3}$ The investigation of structures consisting of $\mathrm{Si}$ nanocrystals (NC) has mostly been aimed at improving their quantum efficiency for photoluminescence (PL) as well as understanding their light absorption and emission mechanisms. In spite of a great number of publications, there is no a consensus about the luminescence mechanisms yet. The discussions are basically centered on whether light emission occurs via quantum confinement or via interface states located at the nanocrystals surface. ${ }^{4-8}$ It is known that several parameters can contribute to the Si NC PL properties, such as the number and size of crystallites, their surrounding and/or competitive nonradiative processes. For instance, it is well

\footnotetext{
${ }^{\text {a) }}$ Author to whom correspondence should be addressed; FAX: +55 513316 6510; electronic mail: uilson@ cefetrs.tche.br

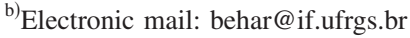

known that passivation of nonradiative interface states enhances the photoluminescence properties of the Si NC without changing the crystallite size., ${ }^{5,6}$ On the other hand, an increase in the $\mathrm{NC}$ dimension makes their light absorption characteristics approach to bulk $\mathrm{Si}$, which means, smaller absorption cross sections. Although large grains have higher electronic density of states, their oscillator strength is smaller ${ }^{9,10}$ and consequently, the radiative recombination rate is lower. ${ }^{10,11}$

$\mathrm{Si} \mathrm{NC}$ embedded in $\mathrm{SiO}_{2}$ matrix have been often produced by using the ion implantation technique. The PL induced by these NC have been usually studied as a function of the implantation fluence, annealing temperature, and annealing time. ${ }^{4-6,12}$ However, up to the moment, the influence of the implantation temperature has scarcely been explored.

On the other hand, it is already known that the PL produced in Si NC is sensitive to the excitation intensity. The previous works ${ }^{11,13,14}$ have shown that a blueshift of the PL spectrum occurs whenever the excitation intensity is increased, but no change in the PL shape was ever observed.

As was previously reported, the PL intensity is a func- 
tion of the excitation intensity and has two regimes. ${ }^{11,13,15} \mathrm{~A}$ linear one, at lower power densities, where the PL intensity increases for all emitting wavelengths with the pump power and a saturation wavelength-dependent regime that starts to manifest by a further increase in the excitation power density. However, as mentioned above when the normalized spectra obtained at different pump powers are compared in the saturation regime, one observes only a blueshift in the PL peak without spectral line shape modification, as the excitation power density is increased.

The present work was undertaken with two major purposes: First, to study the effect of high-temperature Si implantations on the nucleation process of the Si NC and consequently on the PL emission. Second, to investigate the influence of the excitation power density on the PL emission obtained from hot implanted samples. With this aim we have produced $\mathrm{Si} \mathrm{NC}$ by implanting $\mathrm{Si}$ in $\mathrm{SiO}_{2}$ on a wide range of target temperatures, and we have studied the PL emission on a wide range of excitation power densities.

\section{EXPERIMENTAL PROCEDURE}

A 480 nm-thick $\mathrm{SiO}_{2}$ layer thermally grown on (100) $\mathrm{Si}$ wafer was implanted with $170 \mathrm{keV} \mathrm{Si}^{+}$ions at a fluence of $1 \times 10^{17} \mathrm{Si} / \mathrm{cm}^{2}$ providing a peak concentration profile at around $240 \mathrm{~nm}$ depth and an initial Si excess of about $10 \%$. The samples were implanted in a range between room temperature (RT) and $800{ }^{\circ} \mathrm{C}$. The as-implanted samples were further annealed at 1100,1150 , and $1200{ }^{\circ} \mathrm{C}$ under $\mathrm{N}_{2}$ atmosphere in a conventional furnace for $1 \mathrm{~h}$ in order to nucleate and grow the Si precipitates. The PL measurements were performed at RT using a xenon lamp and monochromator in order to get a wavelength of $488 \mathrm{~nm}(2.54 \mathrm{eV})$ as an excitation source. The resulting power density on the samples was about $20 \mathrm{~mW} / \mathrm{cm}^{2}$. The emission was dispersed by a $0.3 \mathrm{~m}$ single spectrometer and detected with a visible-near-infrared silicon detector (wavelength range from 400 to $1080 \mathrm{~nm}$ ).

In order to study the PL dependence on the excitation power density we have used an Ar-ion laser source focused on a circular area with a diameter of about $300 \mu \mathrm{m}$, being the emission detected by a cooled photomultiplier. To cover a wide range of excitation power densities, we have utilized values between 0.002 and $15 \mathrm{~W} / \mathrm{cm}^{2}$. In all cases the spectra were obtained under the same conditions and corrected for the efficiency of the system.

In addition we have performed dark-field cross-sectional transmission electron microscopy (TEM) measurements with a JEOL $200 \mathrm{kV}$ microscope in order to obtain the Si NC size distributions.

\section{RESULTS}

\section{A. PL intensity as a function of the implantation temperature}

In this series of experiments we have used as excitation source a Xe lamp with $20 \mathrm{~mW} / \mathrm{cm}^{2}$ of excitation power density in order to avoid nonlinear effects.

In Fig. 1 are shown typical PL spectra of samples implanted at different temperatures and further annealed at $1100{ }^{\circ} \mathrm{C}$ for $1 \mathrm{~h}$. It can be observed that the PL spectra are

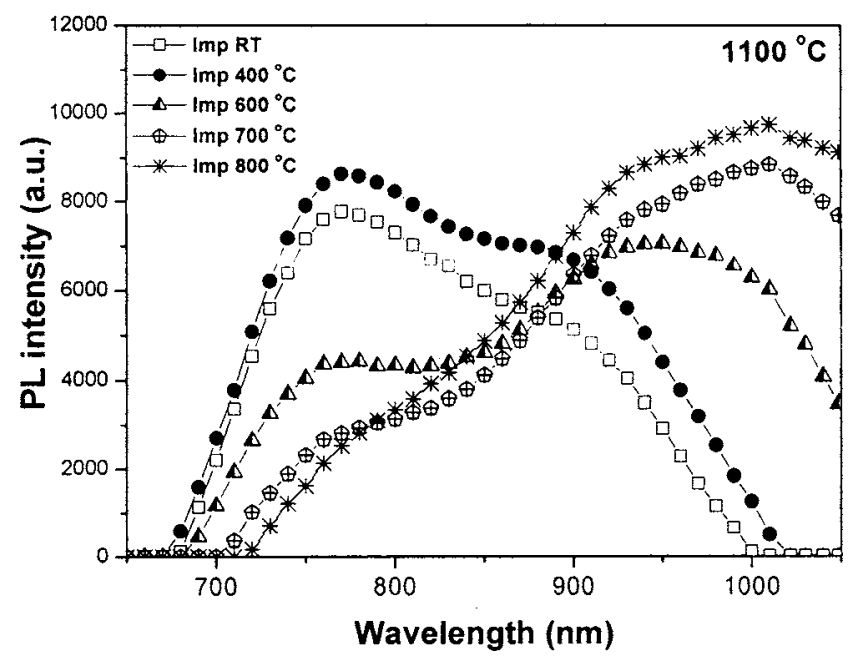

FIG. 1. PL spectra of samples implanted at different temperatures and postannealed at $1100^{\circ} \mathrm{C}$ for $1 \mathrm{~h}$.

broad, ranging from 650 up to $1050 \mathrm{~nm}$, showing a lineshape structure that can be reproduced by two superimposed peaks centered at around 780 and $950 \mathrm{~nm}$, respectively. An inspection of Fig. 1 shows two interesting features: (a) with increasing implantation temperature the PL spectra shift towards longer wavelengths (redshift) and (b) when the implantations were performed at temperatures higher than $400{ }^{\circ} \mathrm{C}$ the PL shape changes considerably. In fact, the PL peak located at the long-wavelength side of the spectrum raises its intensity with increasing implantation temperature.

The thermal annealing temperature also modifies the PL line shape. This behavior is illustrated in Fig. 2, where the PL spectra of samples implanted at RT [Fig. 2(a)] and at $600{ }^{\circ} \mathrm{C}$ [Fig. 2(b)] are displayed for three thermal treatments $\left(1100,1150\right.$, and $\left.1200{ }^{\circ} \mathrm{C}\right)$. Here we can verify that, an increase in the annealing temperature induces a redshift of the whole PL spectrum. Besides, the two-peak structure become less evident for thermal treatments performed at $1200{ }^{\circ} \mathrm{C}$.

All spectra have been fitted with two Gaussians. With this procedure we have determined the wavelength positions $\left(\lambda_{1}\right.$ and $\left.\lambda_{2}\right)$, and the respective intensities $\left(I_{1}\right.$ and $\left.I_{2}\right)$ of the PL peaks-see inset in Fig. 3. The intensities of both PL peaks as a function of the implantation temperature are represented in Fig. 3. The intensity of the peak located at the short-wavelength side $\left(I_{1}\right)$ slightly increases from RT up to $400{ }^{\circ} \mathrm{C}$ and then strongly decreases for higher implantation temperatures, being this behavior independent of the annealing temperature. Conversely, the intensity of the second peak $\left(I_{2}\right)$ increases with the implantation temperature. Exception is the point which belongs to the sample implanted at $800{ }^{\circ} \mathrm{C}$ and annealed at $1150{ }^{\circ} \mathrm{C}$, whose intensity decreases at the same value of the sample implanted at $600{ }^{\circ} \mathrm{C}$. The samples annealed at $1200{ }^{\circ} \mathrm{C}$ show the same behavior (not displayed here) as those annealed at $1150{ }^{\circ} \mathrm{C}$, however, the intensities $I_{1}$ and $I_{2}$ are about $30 \%$ lower.

In Fig. 4 are summarized the peak positions $\lambda_{1}$ and $\lambda_{2}$ as a function of the implantation temperature for the three thermal treatments. Here we can observe two redshifts; one related to the increasing in the annealing temperature and the second due to the increasing in the implantation temperature. 


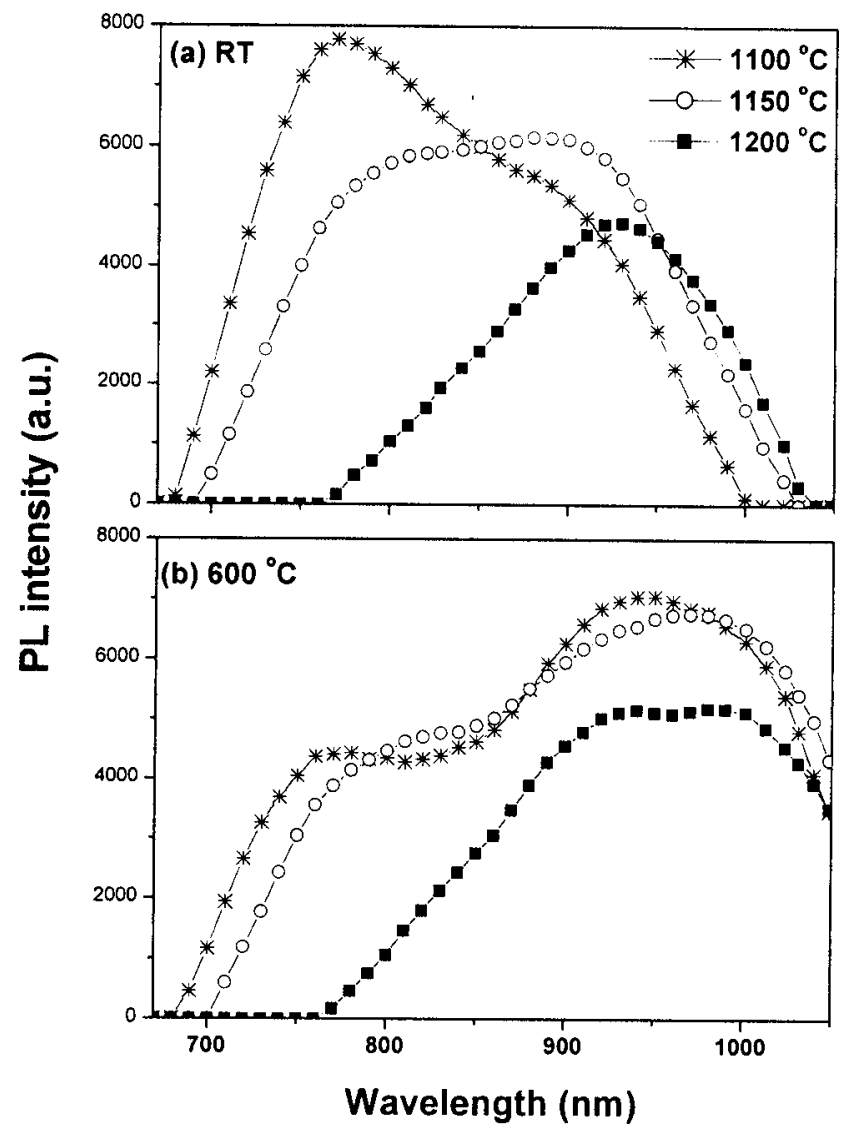

FIG. 2. PL spectra of samples annealed at 1100 (asterisks), 1150 (open circles), and $1200{ }^{\circ} \mathrm{C}$ (full squares) after implantations at (a) RT and (b) $600{ }^{\circ} \mathrm{C}$.

In all the cases increasing annealing temperatures produce a PL redshift for both peaks $\left(\lambda_{1}\right.$ and $\left.\lambda_{2}\right)$. On the other hand, for a given annealing temperature, the first PL peak almost does not change its wavelength; the exceptions are the samples annealed at $1200{ }^{\circ} \mathrm{C}$ where the redshift starts at $600{ }^{\circ} \mathrm{C}$. For

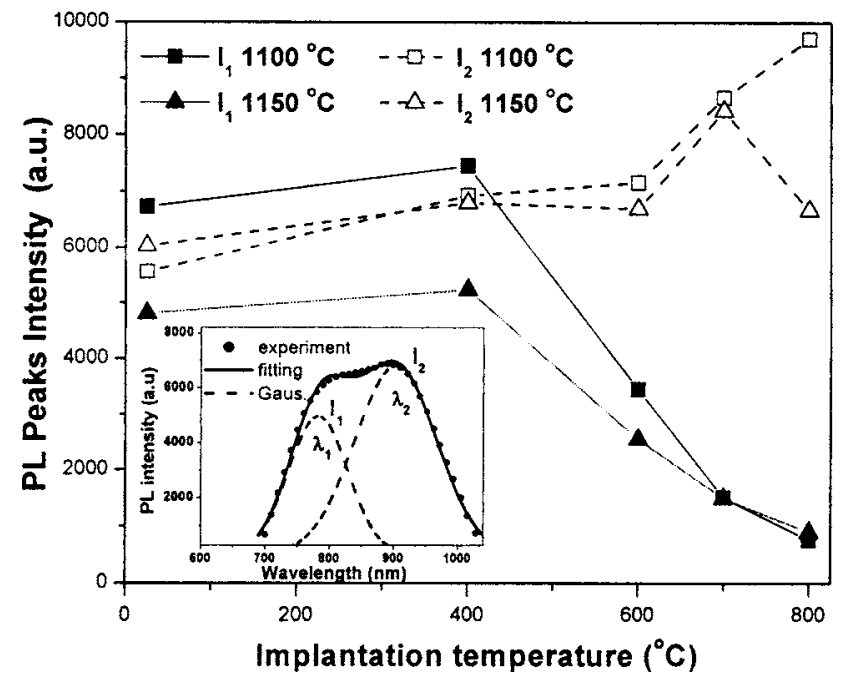

FIG. 3. Intensity of the PL peaks $\left(I_{1}\right.$ and $\left.I_{2}\right)$ as a function of the implantation temperature obtained by fitting the spectra with two Gaussian curves for the samples annealed at 1100 (squares) and $1150{ }^{\circ} \mathrm{C}$ (triangles). The full and open symbols indicate, respectively, the $I_{1}$ and $I_{2}$ PL peak intensities. The inset illustrates the fitting procedure used to obtain the intensities and positions of the peaks.

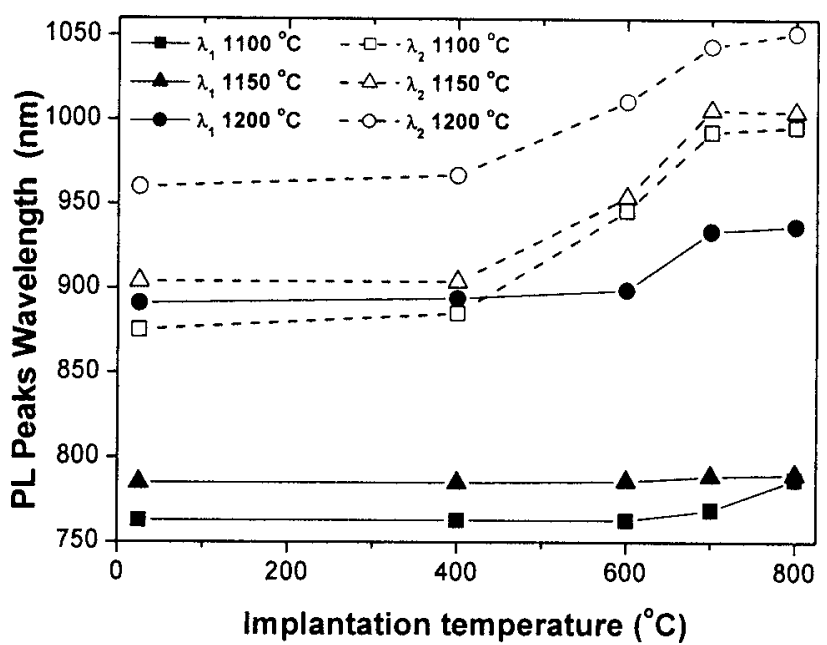

FIG. 4. Wavelength of the PL peaks $\left(\lambda_{1}\right.$ and $\left.\lambda_{2}\right)$ as a function of the implantation temperature, obtained by fitting the spectra with two Gaussian curves for the samples annealed at 1100 (squares), 1150 (triangles), and $1200{ }^{\circ} \mathrm{C}$ (circles). The full and open symbols indicate, respectively, the $\lambda_{1}$ and $\lambda_{2}$ peak positions.

the samples annealed at $1200{ }^{\circ} \mathrm{C}$, the difference in wavelength between the two peaks diminishes when compared with the other annealing temperatures, becoming the structure of two peaks less evident, as already illustrated by Fig. 2.

A second interesting feature displayed in Fig. 4 is the effect of the implantation temperature. One can observe a strong PL redshift of the second peak in those samples which have been implanted at temperatures higher than $400{ }^{\circ} \mathrm{C}$. It increases from 400 up to $700{ }^{\circ} \mathrm{C}$ and then remains stable.

\section{B. PL results as a function of the excitation power density}

In this set of measurements we have employed an Ar-ion laser as excitation source, and we have investigated one sample implanted at $600{ }^{\circ} \mathrm{C}$ and another one implanted at RT, both annealed at $1150{ }^{\circ} \mathrm{C}$.

Figure 5 shows the normalized PL spectra (at $780 \mathrm{~nm}$ ) obtained with different laser power densities. In Fig. 5(a) are shown the PL spectra from the sample implanted at RT for the highest and the lowest excitation power densities. One can observe that the PL peak is blueshifted by $20 \mathrm{~nm}$ from 0.015 to $15 \mathrm{~W} / \mathrm{cm}^{2}$. In this power excitation range the spectra did not show any significative change in shape. On the other hand, the PL from the sample implanted at $600{ }^{\circ} \mathrm{C}$ presents a very different behavior as a function of the laser intensity. An inspection of the Fig. 5(b) clearly shows that as the laser power density decreases from 15 to $0.15 \mathrm{~W} / \mathrm{cm}^{2}$ the spectra shape changes significantly from one to two-peak structure. In fact, the emission at longer wavelengths, which was hidden at higher-power densities, starts to appear. Consequently from 0.15 to $0.015 \mathrm{~W} / \mathrm{cm}^{2}$ the spectral structure peaked at $990 \mathrm{~nm}$ shows up indicating a strong emission contribution from the larger nanocrystals. In addition, from 0.015 to $0.15 \mathrm{~W} / \mathrm{cm}^{2}$, the long-wavelength part of the spectrum is blueshifted for about $35 \mathrm{~nm}$. Decreasing the excitation power density beyond $0.015 \mathrm{~W} / \mathrm{cm}^{2}$ (not shown here) 


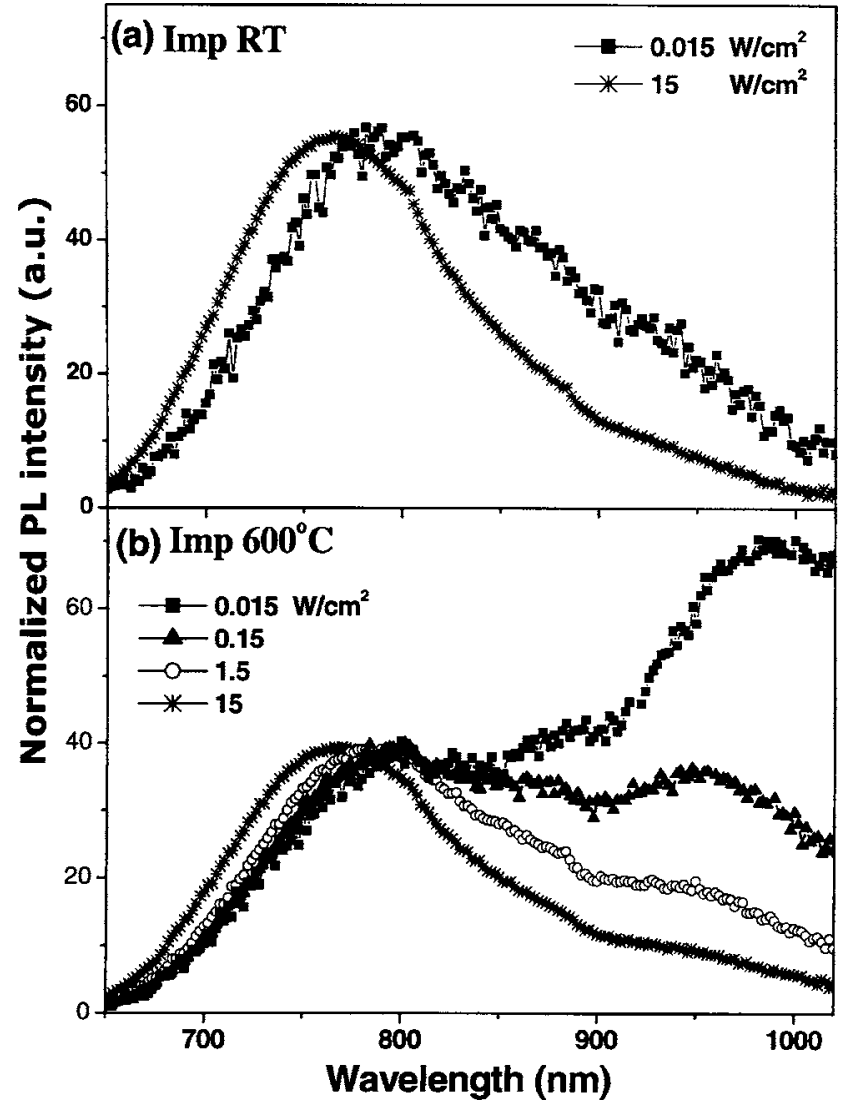

FIG. 5. (a) PL spectra of a sample implanted at RT obtained at 15 and at $0.015 \mathrm{~W} / \mathrm{cm}^{2}$. (b) PL spectra of a sample implanted at $600{ }^{\circ} \mathrm{C}$, measured at different excitation power densities. Both samples were annealed at $1150{ }^{\circ} \mathrm{C}$ for $1 \mathrm{~h}$ and the PL spectra were normalized at $780 \mathrm{~nm}$.

does not produce additional modification in the spectral shape indicating that the linear regime was achieved before. This statement becomes more clear if we observe the graph in Fig. 6 where is shown the PL intensity as a function of the excitation power density for three different wavelengths. It is visible from the figure that by increasing the excitation power density the PL intensity tends to saturate first to longer wavelengths. However, at low excitation densities (enlarged

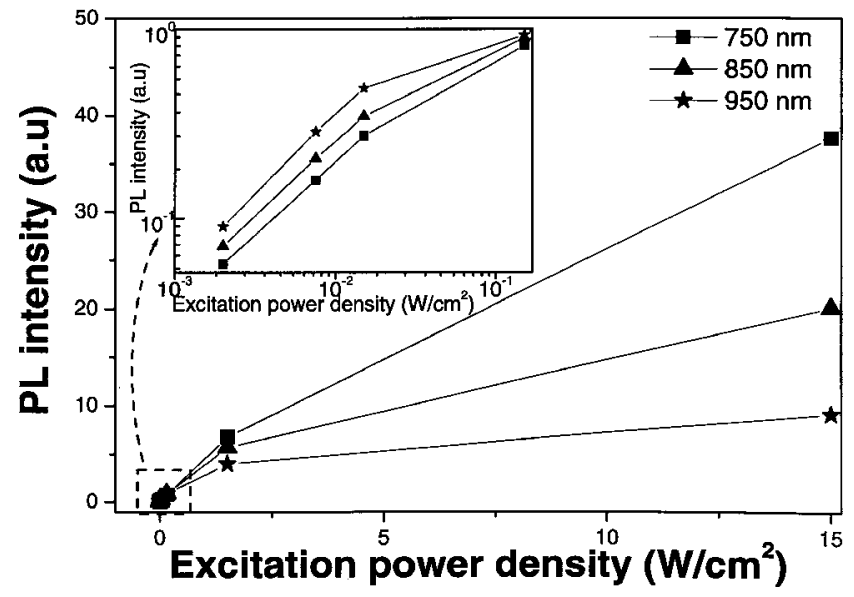

FIG. 6. PL intensity vs excitation power density for three different wavelengths (detection energies) from PL spectra of the sample implanted at $600{ }^{\circ} \mathrm{C}$ and annealed at $1150{ }^{\circ} \mathrm{C}$. The region of low excitation power densities is enlarged in the figure.

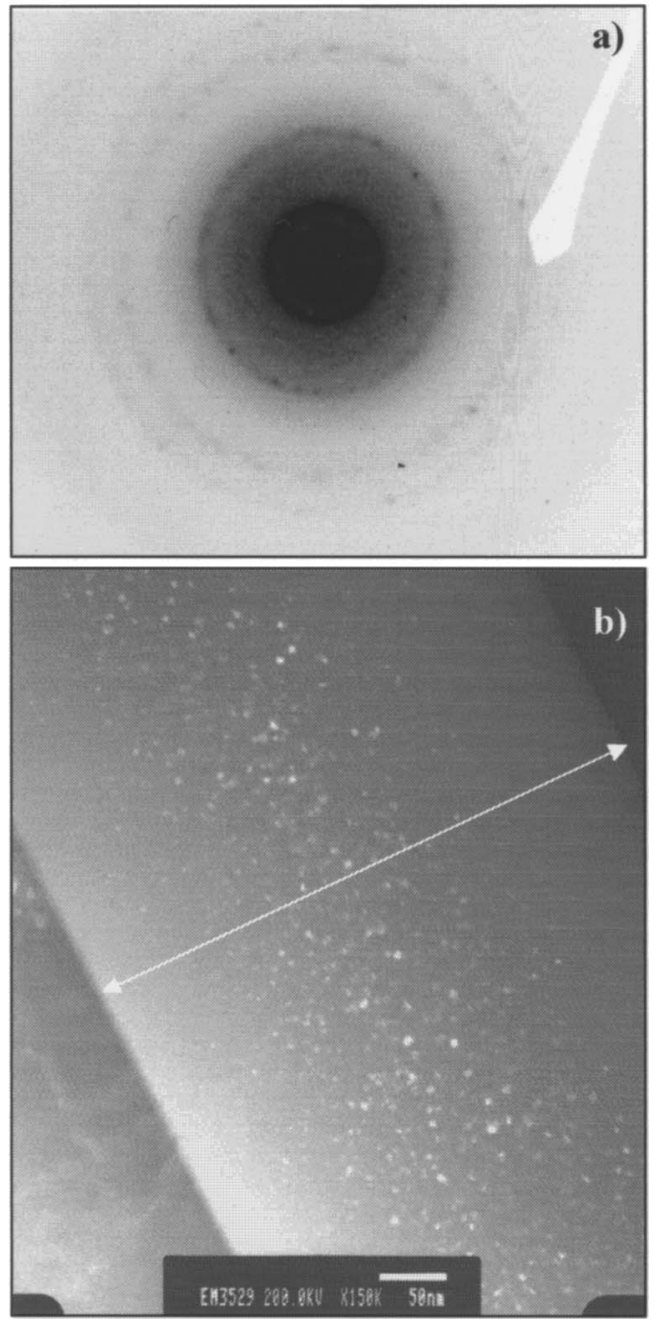

FIG. 7. (a) Diffraction pattern from $\mathrm{Si} \mathrm{NC}$ embedded in an amorphous $\mathrm{SiO}_{2}$ layer. (b) Dark-field TEM image of $\mathrm{Si} \mathrm{NC}$ in a $480 \mathrm{~nm}$-thick $\mathrm{SiO}_{2}$ layer.

region of the figure) the PL intensity at the three wavelengths increases linearly with the laser excitation density up to $0.015 \mathrm{~W} / \mathrm{cm}^{2}$. Then, a transition from the linear regime to the saturation one occurs between 0.015 and $0.15 \mathrm{~W} / \mathrm{cm}^{2}$, being more pronounced for the NC size distribution emitting at longer wavelengths.

\section{TEM observations}

To obtain structural information of our samples we have performed cross-sectional TEM measurements in a dark-field configuration. In order to image the Si NC with high contrast, the diffraction plane aperture was placed at a radius from the center of the diffraction pattern where a Si polycrystalline ring is originated. Under these conditions no amorphous ring and no $\mathrm{Si}$ substrate reflection are found, as indicated in Fig. 7(a). In Fig. 7(b) we show the corresponding image in dark field where we can see the $480 \mathrm{~nm}$-thick $\mathrm{SiO}_{2}$ layer defined by the arrow and the central region where are located the Si NC visible as bright points. We have obtained the $\mathrm{NC}$ size distributions in the $\mathrm{SiO}_{2}$ layers by measuring each nanocrystal diameter in a selected transversal region of the micrograph taken on the whole layer width. 


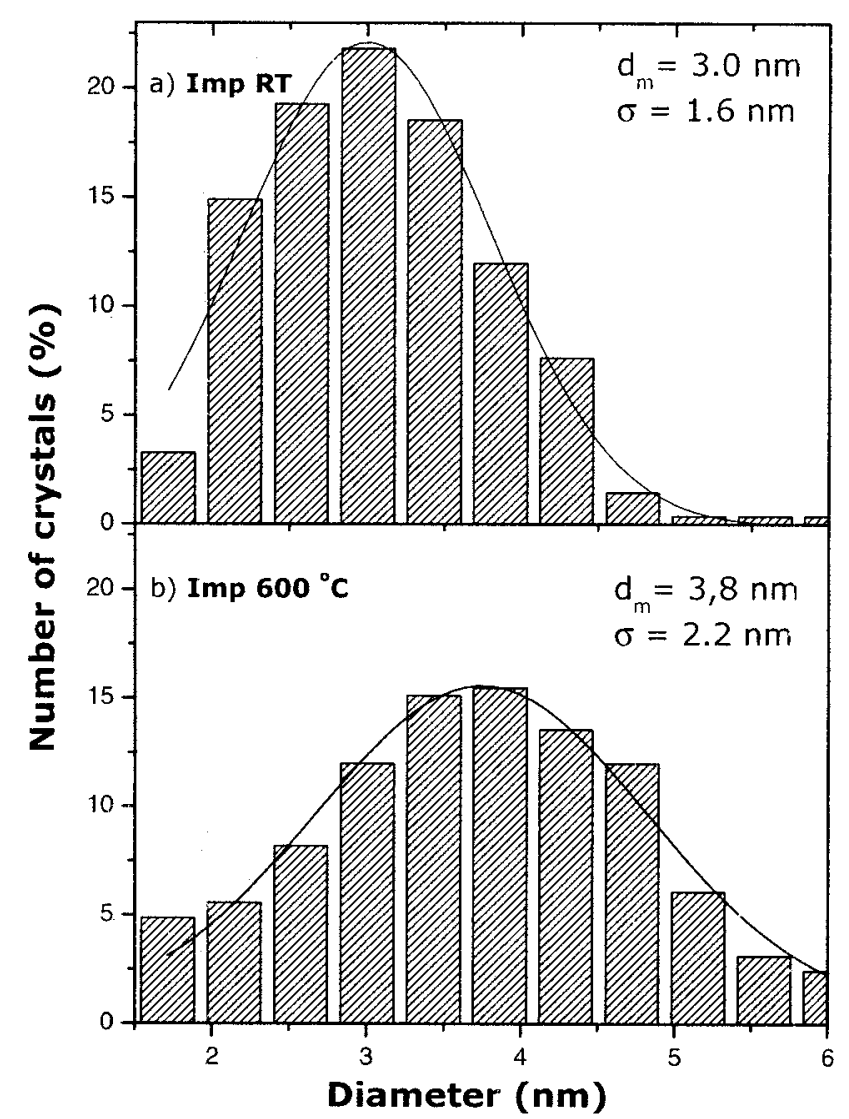

FIG. 8. Size histograms from TEM analyses of a sample implanted at (a) RT and (b) $600{ }^{\circ} \mathrm{C}$ and thermal annealed at $1150{ }^{\circ} \mathrm{C}$.

In Fig. 8 are shown the respective NC size histograms of the RT and $600{ }^{\circ} \mathrm{C}$ implanted samples. For the sample implanted at RT [Fig. 8(a)] we have a NC size distribution with a mean diameter of $3.0 \mathrm{~nm}$ and a full width at half maximum $(\mathrm{FWHM})(\sigma)$ of $1.6 \mathrm{~nm}$, while for the sample implanted at $600{ }^{\circ} \mathrm{C}$ [Fig. 8(b)] these values are 3.8 and $2.2 \mathrm{~nm}$, respectively.

Our TEM observations show that the Si NC mean diameters as well as the width of the size distribution (FWHM) increase with the implantation temperature and also with the annealing temperature (not shown here).

\section{DISCUSSION}

\section{A. High-temperature implants}

The first point to discuss is the relation between the PL line-shape behavior and the implantation temperature. For a given postannealing treatment the strong effect of the implantation temperature starts, in most cases, at around $400{ }^{\circ} \mathrm{C}$-see Figs. 3 and 4 . The peak located at the shortwavelength side reduces its intensity while the second one is enhanced. This is a consequence of the grain-size distribution obtained at each implantation temperature as illustrated by the TEM observations shown in Fig. 8. As can be observed, the higher the implantation temperature, the larger and broader is the Si NC size distribution. The exception is the point corresponding to the $I_{2}$ intensity of the sample implanted at $800{ }^{\circ} \mathrm{C}$ and annealed at $1150{ }^{\circ} \mathrm{C}$-see Fig. 3. This behavior can be explained by the fact that the optimal $\mathrm{NC}$ size has already been achieved at the implantation temperature of $700{ }^{\circ} \mathrm{C}$. The redshift presented by the second peak $\left(\lambda_{2}\right)$ in Fig. 4 is linked to the NC growth. However, for all annealing temperatures is observed a tendency to saturation at around $700{ }^{\circ} \mathrm{C}$. This feature could indicate that at 700 and $800{ }^{\circ} \mathrm{C}$ the $\mathrm{NC}$ size distributions are quite similar.

The prenucleation of the nanocrystals occurs during the high-temperature implantation process. As proposed elsewhere ${ }^{4,16}$ the hot implanted samples contain more nucleation centers (silicon aggregates) formed during the implantation process than those implanted at RT. For a given annealing temperature, an increase in the implantation temperature raises the number of Si NC that will be grown in the $\mathrm{SiO}_{2}$ matrix reducing the interparticle spacing. Besides, it is known that the stability of small crystals depends on the balance between their volume and surface free energies, and as a result their melting point may be much lower than the usual melting temperature. ${ }^{17,18}$ Thus, the interparticle spacing reduction can contribute to concentrate the silicon excess, growing larger crystallites subsequent to the annealing when the samples are hot implanted. Hence, implantations at high temperatures should facilitate the growth process during annealing as well.

As already reported, larger crystallites are formed by increasing the annealing temperature. ${ }^{19}$ This explains the redshift of both peaks, as can be observed in Fig. 4. In agreement with the quantum confinement theory, the progressive redshift of the PL peaks with increasing crystal size is due to the reduction of the band gap of the Si NC, approaching to that of the bulk crystalline silicon.

The PL line shape and intensity depend on the density of crystallites in the $\mathrm{SiO}_{2}$ matrix and their size. The $\mathrm{Si} \mathrm{NC}$ absorption cross section is basically related to its oscillator strength and the electronic density of states. While the first decreases, the second one increases with increasing grain size. Then, there is a critical size for which the luminescence signal reaches its maximum. In addition, depending on the distance between nanocrystals, a decrease in the PL intensity can be related to a partial annihilation of quantum confinement by tunnel effects and/or other nanocrystals interactions. ${ }^{19,20}$ Thus, by observing the data shown in Fig. 3, we see that both peaks $\left(I_{1}\right.$ and $\left.I_{2}\right)$ typically present higher PL intensity for the samples annealed at $1100{ }^{\circ} \mathrm{C}$. In this way, we can assume that the optimal crystallite size was achieved at this annealing temperature, independent of the implantation temperature.

\section{B. Influence of the excitation power density}

PL spectra from Si NC produced by RT implantation do not show any significative change in their shapes with the excitation power density as illustrated by Fig. 5(a). On the other hand, the $600{ }^{\circ} \mathrm{C}$ implantation originates a PL spectrum strongly dependent on the excitation power densitysee Fig. 5(b). This feature is closely related to the NC size distribution, produced in each implantation, as revealed by the TEM observations. The corresponding grain-size histograms displayed on Fig. 8 confirm that hot implantation generates broader Si NC distributions with a larger mean diam- 
eter as compared with RT implantation. We have also obtained a broad Si NC distribution with larger grains for samples implanted at RT but annealed at $1200{ }^{\circ} \mathrm{C}$ (not shown here). Consequently, a similar PL emission behavior was found as compared with that observed for the $600{ }^{\circ} \mathrm{C}$ implanted sample.

The present results can be explained by a nanoparticle model, which assumes independent absorption and luminescence process of the different particles. It is well known that Si nanostructures, whose emission mechanism is strongly related to the quantum confinement, present different PL decay dynamics depending on the nanoparticles size. ${ }^{11,14,21,22}$ The time decay of the PL is faster with decreasing emission wavelength. It means that nanocrystals which emit at longer wavelengths decay at a slower rate as compared with those which emit at shorter wavelengths. The size-dependent radiative decay rate can be correlated to the electron-hole exchange energy $\Delta$, which also depends on the nanocrystal size. According to the Calcott et $a .^{23}$ model, applied by Brongersma et $a l .{ }^{24}$ to Si NC produced by ion implantation, the exchange electron-hole interaction splits the excitonic levels by an energy $\Delta$. The lowest level in this splitting is a triplet state and the upper level is a singlet one. The triplet state has a radiative decay rate $R_{T}$ much smaller than the radiative decay rate $R_{S}$ of the singlet. The splitting $\Delta$ as shown in Ref. 24 increases with the emission energy, raising consequently the ratio $R_{S} / R_{T}$. Hence, if the excitation power density is increased, the low-energy part of the PL spectrum reaches first its saturation level, while the high-energy part of the spectrum continues in the linear range. Thus, the larger grains emission gets hidden behind the smaller nanoparticles emission, which remains proportional to the increasing of the excitation power density. In addition, in the saturation regime the Auger process has a large contribution on the nonradiative recombination, quenching the PL. This effect, discussed in details by Kovalev et al. ${ }^{15}$ is stronger for larger nanocrystals which have larger absorption cross section and longer radiative lifetime.

\section{CONCLUSIONS}

We have investigated the photoluminescence behavior of Si NC produced by Si implantations at high temperature in a $\mathrm{SiO}_{2}$ matrix. By using low excitation power density (far from saturation regime for all $\mathrm{NC}$ sizes) it was possible to obtain the PL spectrum without nonlinear effects. We have observed a PL line structure that can be reproduced by two superimposed peaks which are strongly dependent of the implantation temperature. As the annealing temperature was increased both PL peaks shifted towards the long wavelengths (redshift). The influence of the implantation temperature is remarkable for $T>400{ }^{\circ} \mathrm{C}$, where the intensity of the peak located at the short-wavelength side decreases considerably, while the other one, at longer wavelengths, increases. This second peak also presents a continuous redshift as the implantation temperature is raised. In addition it was shown that the implantation temperature enhances the grow process of the Si NC during the postannealing treatment performed at high temperatures.

On the other hand, we have shown that whenever a broad size distribution of nanoparticles is produced with the presence of large grains, special attention should be paid to the excitation power density. In this case low excitation intensity should be used in order to get the full PL spectrum. Otherwise, high excitation power density will produce a partial PL spectrum with only the high-energy emission components from the smaller nanoparticles. It is important to consider the excitation regime that the experiment has been done before making any correlations between optical and structural properties, as well as when tailoring the system for eventual device applications.

The authors gratefully acknowledge financial support from CNPq (H.B and U.S.S.) FAPESP (ER). We are grateful to GPO-IFGW-UNICAMP for technical support.

${ }^{1}$ L. Pavesi, L. Dal Negro, C. Mazzoleni, G. Franzò, and F. Priolo, Nature (London) 408, 440 (2000).

${ }^{2}$ A. T. Fiory and N. M. Ravindra, J. Electron. Mater. 32, 1043 (2003).

${ }^{3}$ L. Brus, in Semiconductors and Semimetals, edited by D. Lockwood (Academic, New York, 1998), Vol. 49, p. 303.

${ }^{4}$ T. S. Iwayama, D. E. Hole, and I. W. Boyd, J. Phys.: Condens. Matter 11, 6595 (1999).

${ }^{5}$ B. Garrido Fernandez, M. Lóppez, C. Garcíra, A. Pérez-Rodríguez, J. R. Morante, C. Bonafos, M. Carrada, and A. Claverie, J. Appl. Phys. 91, 798 (2002).

${ }^{6}$ S. Cheylan and R. G. Elliman, Appl. Phys. Lett. 78, 1912 (2001).

${ }^{7}$ G. Ledoux, J. Gong, F. Huisken, O. Guillois, and C. Reynaud, Appl. Phys. Lett. 80, 4834 (2002).

${ }^{8}$ V. I. Klimov, Ch. Schwarz, D. McBranch, and C. W. White, Appl. Phys. Lett. 73, 2603 (1998).

${ }^{9}$ D. Kovalev, J. Diener, H. Heckler, G. Polisski, N. Künzner, and F. Koch, Phys. Rev. B 61, 4485 (2000).

${ }^{10}$ M. López et al., Appl. Phys. Lett. 80, 1637 (2002).

${ }^{11}$ V. Vicinguerra, G. Franzò, F. Priolo, F. Iacona, and C. Spinella, J. Appl. Phys. 87, 8165 (2000).

${ }^{12}$ G. H. Li, K. Ding, Y. Chen, H. X. Han, and Z. P. Wang, J. Appl. Phys. 88, 1439 (2000).

${ }^{13}$ M. Koós, I. Pócsik, and É. B. Vázsonyi, Appl. Phys. Lett. 62, 1797 (1993).

${ }^{14}$ A. Hryciw, A. Meldrum, K. S. Buchanan, and C. W. White, Nucl. Instrum. Methods Phys. Res. B 222, 469 (2004).

${ }^{15}$ D. Kovalev, H. Heckler, G. Polisski, and F. Koch, Phys. Status Solidi B 215, 871 (1999).

${ }^{16}$ U. S. Sias, E. C. Moreira, E. Ribeiro, H. Boudinov, L. Amaral, and M. Behar, J. Appl. Phys. 95, 5053 (2004).

${ }^{17}$ A. N. Goldstein, Appl. Phys. A: Mater. Sci. Process. 62, 33 (1996).

${ }^{18}$ S. Veprek, Thin Solid Films 297, 145 (1997).

${ }^{19}$ F. Iacona, G. Franzò, and C. Spinella, J. Appl. Phys. 87, 1295 (2000).

${ }^{20}$ M. Lopez, B. Garrido, C. Bonafos, O. González-Varona, A. PérezRodríguez, J. Montserrat, and J. R. Morante, Microelectron. Reliab. 40, 859 (2000).

${ }^{21}$ C. Garcia, B. Garrido, P. Pellegrino, R. Ferre, J. A. Moreno, J. R. Morante, L. Pavesi, and M. Cazzanelli, Appl. Phys. Lett. 82, 1595 (2003).

${ }^{22}$ J. Linnros, N. Lalic, A. Galeckas, and V. Grivickas, J. Appl. Phys. 86, 6128 (1999).

${ }^{23}$ P. D. J. Calcott, K. J. Nash, L. T. Canham, M. J. Kane, and D. Brumhead, J. Phys.: Condens. Matter 5, L91 (1993).

${ }^{24}$ M. L. Brongersma, P. G. Kik, A. Polman, K. S. Min, and H. A. Atwater, Appl. Phys. Lett. 76, 351 (2000). 